\title{
A standard primary energy approach for comparing desalination processes
}

\author{
Muhammad Wakil Shahzad (D), Muhammad Burhan ${ }^{1}$ and Kim Choom Ng (D)
}

Considering different grades of energy as equivalent in the desalination industry could have negative economic and environmental consequences. Whereas this approach will suffice for the comparison of same energy input processes, omitting the grade of energy when comparing diverse technologies may lead to incorrect conclusions and, resultantly, inefficient installations. Here, a standard primary energy-based thermodynamic framework is presented that addresses the energy efficacy of assorted desalination processes. Example calculations show that a thermal desalination plant integrated with a power plant consumes 2-3\% of input standard primary energy. We also propose a standard universal performance ratio methodology to provide a level playing field for the comparison of desalination processes; this suggest that the majority of desalination processes are operating far from the sustainable zone, with only $\sim 10-13 \%$ at the ideal or thermodynamic limit. A proposed roadmap shows that attaining an efficacy level of up to $25-30 \%$ of the thermodynamic limit is crucial for achieving the 2030 sustainability development goals for seawater desalination, which will require a technological shift in the capability of dissolved salts separation processes.

npj Clean Water (2019)2:1; https://doi.org/10.1038/s41545-018-0028-4

\section{INTRODUCTION}

Water, energy, and environment nexus is important for future sustainability. In 2000, the overall world water demand was 4000 billion cubic meter (BCM) and it is estimated to increase over $58 \%$ by 2030 . Water is considered as a crucial link between society and environment and its demand is increasing with improved life style. In Gulf cooperation council (GCC) countries, the water demand is expected to grow up to 46 BCM by 2030 as compared to 28 BCM in 2000 as shown in Fig. $1 a^{1-3}$ The current fresh water sources are not sufficient to fulfill the increasing water demand. The projected demand of potable water can only be supplied by seawater desalination processes. It has been reported that the world's desalination capacities may be doubled by 2030 with the current cumulative annual growth rates as shown in Fig. $1 b^{1-3}$

Currently, the share of seawater reverse osmosis (SWRO) processes is $60 \%$ of the world desalination market due to the dropping of its specific energy consumption from 17 to $3.5 \mathrm{kWh}$ electricity $/ \mathrm{m}^{3}$ since the $1970 \mathrm{~s}$. Such improvement can be attributed to the development of better performance thin-film composite membranes, the energy recovery devices integration and the improved pretreatment processes. The remaining $40 \%$ share of desalinated water is produced by thermally driven processes such as the multi effect desalination (MED) and the multi stage flash (MSF) processes those consumes electricity as well as low-grade steam at $60-90 \mathrm{kWh}$ thermal $/ \mathrm{m}^{3}$, as reported in the literature. ${ }^{4-7}$ To an unsuspecting consumer or operator of desalination plants, the specific energy consumption of desalination processes may have assumed the equivalency between units of energy of electricity and the low-grade steam. In this article, the authors make a clear distinction between the assorted grades of energy supplied to desalination processes, particularly both the quantitative and qualitative aspects of electricity and the steam. By discerning the grade of energy consumed in the desalination plants, only then one can make a just and accurate comparison of these desalination methods. The total energy consumption for desalination is expected to reach to $2.4 \mathrm{GWh}$ in 2030 as compared to only $1.4 \mathrm{GWh}$ in 2018 with projected expansion of desalination capacities.

Energy production has an explicable implications on the water consumption and almost $15 \%$ of total water consumption of the world can be attributed to the power generation processes. It is estimated that electricity generation capacity will increase to over $70 \%$ by 2030 as compared to current annual 25,000 TWh installed production capacities. The traditional power plant efficiencies varies from 38 to $50 \%$ in terms of primary energy transformation to the secondary or derived energy. The chronological trend of power plants efficiency improvement since 1880 s can be observed in Fig. $2 .^{8-15}$ It can be noticed that from 1880 to 1970 , only a marginal efficiency improvement from $26 \%$ to $33 \%$ was observed that spanned over a century due to the "bottle necks" arising from conventional heat and mass transfer processes. A significant increase from $33 \%$ to $50 \%$ was observed during 1970 to 2000 and it was attributed to the implementation of efficient combined cycle gas turbines (CCGT) cycle and concomitantly, a quantum reduction in environmental pollution was also noted. Today, the co-generation of electricity, steam and desalinated water via improved CCGTs have recorded an overall energy efficiency at a benchmark of $58 \%$ of the thermodynamic limit, one of the most efficient cycle reported in the commercial market. However, General Electric (GE) with the partnership of ENGIE (formerly known as Electricity De France or EDF) set a world record by achieving a $62 \%$ efficiency of the most advanced combined-cycle (CCGT) power plant operating at Japan. ${ }^{16}$ This large range in conversion efficiencies is due to the rapid development of temperature-cascaded combined cycles, converting more than half of fossil fuel energy to useful electricity, in contrast to about one-third efficiency of the stand-alone gas turbine cycles. The key

\footnotetext{
${ }^{1}$ Water Desalination and Reuse Centre, King Abdullah University of Science and Technology, Thuwal 23955-6900, Saudi Arabia

Correspondence: Muhammad Wakil. Shahzad (muhammad.shahzad@kaust.edu.sa)
}

Received: 20 April 2018 Accepted: 21 November 2018

Published online: 07 January 2019 

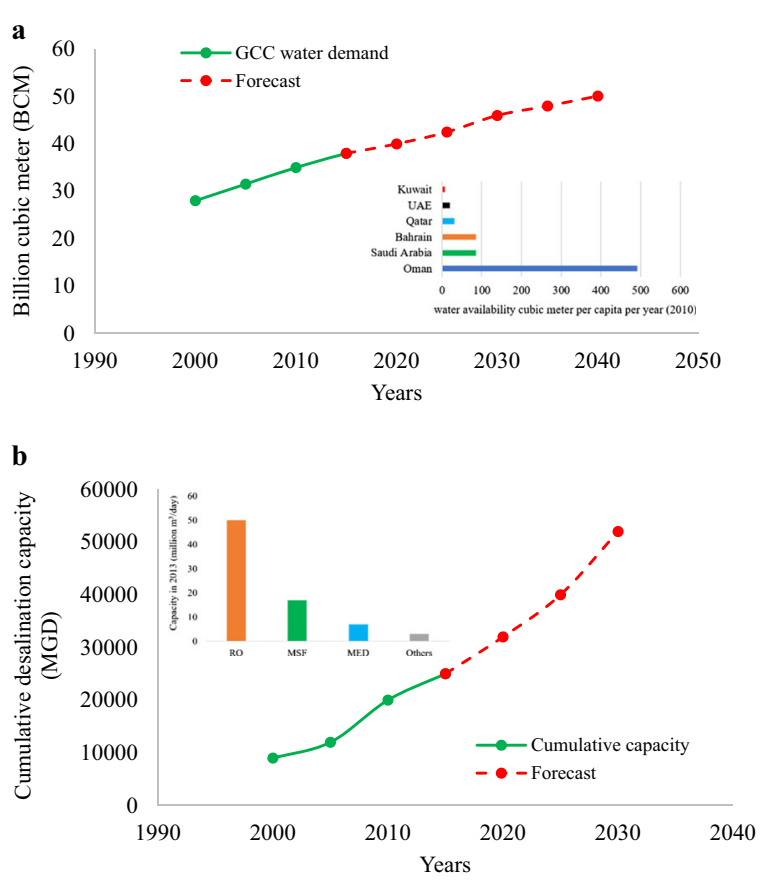

Fig. 1 a Water demand trend from 1990 to 2040 in the gulf cooperation council countries and $\mathbf{b}$ Global cumulative desalination trend and forecast up to 2030

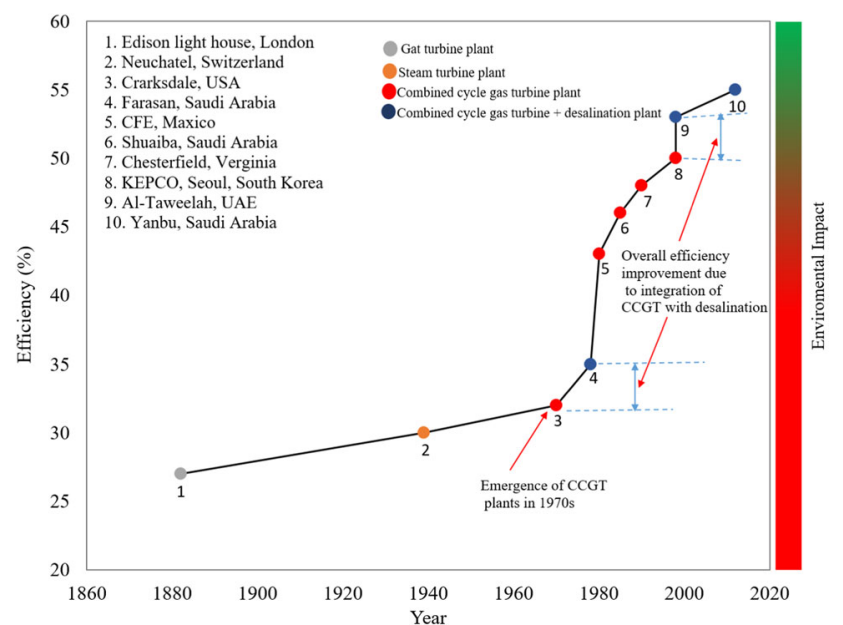

Fig. 2 Overall plant efficiency and environment impact of primary energy conversion plants

breakthrough in improved cycle was the careful incorporation of a temperature-cascaded hybrid processes to maximize the utilization of the input fuel exergy. This also highlighted the need for a detailed thermodynamic framework to estimate the distribution of the exergy utilization in combine cycle processes with respect to their operational parameters.

In a CCGT configuration, first, the input exergy of primary fuel is utilized to produce electricity by a gas turbine (GT) cycle and its exhaust gas exergy is further recovered via an efficient heat recovery steam generator (HRSG) for steam generation to produce more electricity through the steam turbines (STs). Today's CCGT are operating in tandem with the seawater desalination processes, achieving the best overall energy efficiency up to 58\%. According to the published literature based on convention energetic analysis, the gas turbines (GT) consumes $72 \pm 3 \%$ of the input fuel exergy and the heat recovery steam generator (HRSG) salvages up to $28 \pm 3 \%$ of the remaining exergy of fuel from the GT exhaust gases to generate steam for steam turbine cycle. ${ }^{17,18}$ Only a fraction $4 \pm 1 \%$ of the input exergy is bled-off as a lowgrade steam that matches thermodynamically the evaporative requirements of thermally driven desalination processes. This concept of maximizing the thermodynamic exergy of primary fuel for the simultaneous production of electricity and desalinated water is therefore deemed as the de facto standard. Even though the combined power and water production scheme is most favorable but their analysis is more tedious due to different grades of energy utilization by the processes. There are lot of publications on combined CCGT power and desalination cycle analysis based on energetic and exergetic analysis, but no one is widely accepted due to limitations with all existing methodologies.

Since 1970s, many authors presented first law of thermodynamics for co-generation-based desalination processes fuel cost allocation. For example, Burly ${ }^{19}$ and Al-Sofi et al. ${ }^{20}$ utilized the enthalpy and flow rate of bleed steam to estimate the proportions primary fuel to desalination processes. Seven different methods for fuel cost allocation proposed by Wang et al. ${ }^{21}$ also based on energy of input streams and outputs. Hamed et al. ${ }^{22}$ presented energetic-based desalinated water cost for a real co-generation based desalination plant. Helal ${ }^{23}$ and Lozano et al. ${ }^{24}$ proposed trigeneration (power, desalination, and cooling) plant energetic analysis based on distribution of heat energy. The quantitative or energetic analysis may deemed sufficient for a comparative exercise only when the processes utilize same form of the energy, such as SWRO to SWRO and MED to MED. However, when the comparison is made across desalination processes having assorted forms of derived energy as input, quantative as well as qualitative analysis is required. This can be achieved by invoking the 2nd Law of thermodynamics and exergetic analysis approaches.

Although, number of publications are available on exergy analysis, but they only focused on system performances in case of single purpose plants and components performance improvement of the dual purpose plants. May authors presented second law of thermodynamic analysis of desalination processes with different efficiency definitions. ${ }^{25-31}$ For example, J.H. Lienhard et al. ${ }^{32}$ conducted a detailed exergetic analysis only for desalination processes. They presented the second law efficiency by considering desalination processes as a black box and the ideal work or thermodynamic limit for separation of dissolved salts in seawater is used as the Carnot work. They considered stand-alone processes for their analysis and it was not linked to co-generation based current practices. Similarly, K.H. Mistry et al. ${ }^{33-35}$ presented entropy generation in different desalination processes and second law efficiency without considering secondary energy generation processes, i.e., with no bearing to the best available co-generation processes being used in power generation industry of today. Such independent approaches, although correct in analyses by themselves, but do not reflect the chorological evolvement of efficient production of secondary or derived energy sources. Fitzsimons et al. $^{36}$ summarized over 60 publications on exergy analysis but all are based on stand-alone processes analysis with differences in calculated values up to $80 \%$ due to various assumptions and calculation methodologies 37,38 .

It can be noticed that, there are two major gaps in published literature. First, most of the literature is based on conventional energetic approach for combined power and desalination processes analysis that provides unfair apportionment of primary fuel due to ignoring the grade of energies utilized by the processes. Second, there is no common platform to compare all desalination processes by incorporating different grades of energies in CCGT arrangement. Even within thermally driven processes such as multi effect desalination (MED) and multi stage flash (MSF) the activation steam temperatures are different. Conventionally, desalination processes are presented based on different kind of energy for comparison purposes, such as electricity $(\mathrm{kWh})$ and thermal $(\mathrm{kWh})$. Even though 
the units are same but this comparison is not fair as grade of energies are different. In this paper, we developed a detailed thermodynamic framework based on standard primary energy (SPE) approach to resolve two main issues, namely; (i) an accurate apportionment of primary fuel exergy across each processes in a combined cycle arrangement based on their operational parameters and (ii) comparison of all desalination processes at common platform called standard universal performance ratio (SUPR) by converting different type and grade of energies to standard primary energy. This can be achieved by invoking the $2^{\text {nd }}$ Law of thermodynamics where the primary energy can be supplied to achieve the same equivalent work of the separation processes. The proposed approach circumvents the deficiency of derived energy units ( $\mathrm{kWh}$ ) used singly as these energy units omits the quality of supplied energy.

Table 1. Summary of GT, ST and CCGT + desalination plants analysis

\begin{tabular}{|c|c|c|c|}
\hline & $\begin{array}{l}\text { Carnot } \\
\text { work }\end{array}$ & $\begin{array}{l}\text { Exergy } \\
\text { destruction }\end{array}$ & $\begin{array}{l}\text { Cumulative exergy } \\
\text { destruction }\end{array}$ \\
\hline & $(\mathrm{MW})$ & (\%) & MW \\
\hline \multicolumn{4}{|l|}{ Gas turbine cycle } \\
\hline GT & 562.47 & 58.22 & 58.22 \\
\hline Exhaust gas to ambient & 18.03 & & \\
\hline $\begin{array}{l}\text { Un-accounted losses } \\
\text { share }\end{array}$ & 20.97 & & \\
\hline Sub-total & 601.48 & & \\
\hline $2^{\text {nd }}$ law efficiency & $64.5 \%$ & & \\
\hline \multicolumn{4}{|l|}{ Steam turbine cycle } \\
\hline ST & 298.43 & 38.95 & 97.17 \\
\hline Re-heating & 21.36 & & \\
\hline HRSG losses share & 52.04 & & \\
\hline Condenser losses share & 19.41 & & \\
\hline $\begin{array}{l}\text { Un-accounted losses } \\
\text { share }\end{array}$ & 11.13 & & \\
\hline Sub-total & 402.38 & & \\
\hline $2^{\text {nd }}$ law efficiency & $50.1 \%$ & & \\
\hline \multicolumn{4}{|c|}{ Multi effect desalination cycle } \\
\hline MED heat source & 18.28 & 2.83 & 100 \\
\hline TVC & 5.79 & & \\
\hline HRSG losses share & 3.19 & & \\
\hline Condenser losses share & 1.19 & & \\
\hline $\begin{array}{l}\text { Un-accounted losses } \\
\text { share }\end{array}$ & 0.682 & & \\
\hline Sub-total & 29.14 & & \\
\hline \multicolumn{4}{|c|}{ Conversion factors from derived energy to SPE } \\
\hline $\begin{array}{l}\text { For CCGT electricity } \\
\text { (weighted factor) }\end{array}$ & 2.012 & (equivalent to & 49.7\% CCGT efficiency \\
\hline For MED & 35.33 & & \\
\hline
\end{tabular}

The standard primary energy (SPE) approach consider meaningful temperature ratios to complete thermodynamic cycle, from the adiabatic flame temperature to the ambient reservoir. The proposed SPE methodology have two requisite. First, it is important to consider the current best available practice of power and water production. Second, the operating inlet and out temperatures of actual separation processes in the form of work or heat should be normalized to a common standard inlet and outlet temperatures. The results and detailed methodology are presented in the following sections.

\section{RESULTS AND DISCUSSION}

In any separator device, the governing $2^{\text {nd }}$ Law equations and efficiencies are representing the work and heat-driven desalination methods. The gas turbine cycle, including its all components, consume $58.22 \%$ of input fuel exergy while remaining exergy in exhaust gases is recovered through exhaust gases operated HRSG. The steam turbine cycle extract $38.95 \%$ of input fuel exergy via steam produced in HRSG and it also include internal losses in the cycle and part of steam exergy dumped in the condenser. The bleed steam for MED cycle, including heat input and thermal vapor compressor carries only $2.83 \%$ of input fuel exergy. The MED exergy proportion also includes the share condenser steam and unaccounted losses. For convenience of the engineers and scientists in the industry, the concept of conversion factors (CFs) is proposed to convert the derived energies input to the SPE input as summarized in Table 1. It shows that to produce one unit of electricity, power plant consume 2.012 unit of SPE. Similarly, one unit of SPE can produce 35.33 unit of low-pressure steam to operate MED.

The proposed SPE approach has clear advantages over previously published conventional energetic and primary energy (PE) methodologies ${ }^{39,40}$ as it can maximize the potential by considering the extreme temperature of a process, adiabatic flame temperature to the ambient. This methodology is more accurate for input energy apportionment by considering the equivalent work approach. The performance of desalination plants, conventionally reported based on the derived energies, can now be transformed equitably on a common platform based on SPE. This new improved figure of merit, called the standard universal performance ratio (SUPR), is calculated based on SPE and presented in Table $2 .^{39,40}$ It can be noticed that all desalination processes are operating at only $10-13 \%$ of thermodynamic limit (TL). These low efficiency levels are deemed unsustainable for future desalinated water supplies. We opine that there is much room to improve the efficacy of seawater desalination processes to achieve SUPR $25-30 \%$ by developing better materials or processes in the near future. One credible and near target solution for seawater desalination processes improvement is the incorporation of hybrid processes that can stretch the operational limits of existing proven conventional desalination technologies. For example, an improved MED performance is demonstrated with

Table 2. SPE and SUPR calculation of major desalination processes

\begin{tabular}{|c|c|c|c|}
\hline Thermal (kWh_ther $\left./ \mathrm{m}^{3}\right)[39,40]$ & - & 90.0 & 70.0 \\
\hline Conversion factor for electricity (weighted $\mathrm{CF}_{\text {elec }}$ ) & 2.012 & & \\
\hline Conversion factor for thermal for less than $130^{\circ} \mathrm{C}$ operation $\left(\mathrm{CF}_{\text {ther }}\right)$ & - & 35.33 & \\
\hline $\begin{array}{l}\text { Standard primary energy }\left(Q_{-S P E}\right) \\
Q_{S P E}=\left[\left(k^{\prime} h_{\text {elec }} / \mathrm{m}^{3}\right)\left(\mathrm{CF}_{\text {elec }}\right)\right]+\left[\left(\mathrm{kWh}_{\text {ther }} / \mathrm{m}^{3}\right)\left(\mathrm{CF}_{\text {ther }}\right)\right]\end{array}$ & 7.12 & 8.22 & 6.00 \\
\hline SUPR $\%$ of thermodynamic limit (SUPR $=828$ at TL) & $10.9 \%$ & $9.5 \%$ & $13.0 \%$ \\
\hline
\end{tabular}


the use of a thermal vapor compressor ${ }^{41}$ that enhances the heat transfer of film evaporation on tube surfaces of MEDs. Recently, the research on hybrid MEDAD ${ }^{42-46}$ along with TVC depicted a boost in water production up to twofolds due to the stretch of lower brine temperature to as low as $7^{\circ} \mathrm{C}$ due to sorption kinetics of silica-gel adsorbents. The exergy of the evaporation and condensation processes in the hybrid cycles are synergized thermodynamically to boost the water production.

\section{Future roadmap for desalination processes}

As the existing desalination processes are still far from the thermodynamic limit, there is an urgent motivation to improve desalination processes for future sustainable water supplies. To approach higher efficiency levels, the utilization of input fuel exergy must be maximized with excellent thermodynamic synergy between processes. For future sustainability, an alternatively, new "out-of-box" solution(s) are needed.

In addition, for a future roadmap, lessons can be learned from the past experience of seawater desalination processes. Figure 3 shows the trend of performance improvement of desalination processes from $1500 \mathrm{~s}$ when desalination was started on ships only. It can be seen that every quantum jump in the efficacy of seawater desalination can only be achieved by a corresponding

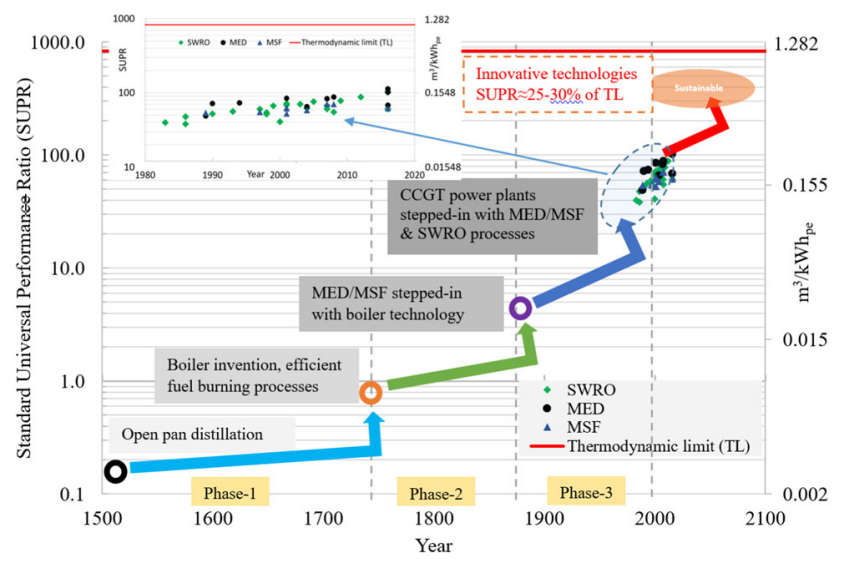

Fig. 3 Desalination roadmap to achieve future sustainable desalination goals paradigm change in technology. The gradual improvements in existing methods, namely the better methods of handling the dissolved salts scaling/fouling and prevention of bio-fouling, can only provide a marginal increase in the efficiency. This was the reason of almost no improvement in desalination processes efficiency since last three decades. We opine that the continued research in assorted seawater desalination processes to nurture "out-of-box" solutions will contribute to a major development in the performance in the near future. The current hybridization trends $^{47-56}$ and the graphene-based membranes ${ }^{57-62}$ will exhibit a possible next quantum jump in desalination efficacy towards achieving the 25 to $30 \%$ of the TL which will then address the future goals of sustainable seawater desalination.

\section{METHODS}

A detailed thermodynamic framework is developed for SPE approach based on equivalent work methodology. A typical CCGT + desalination plant with operational parameters is presented in Fig. 4 and all state points are summarized in Table 3 . The detailed calculation methodology is provided in Table 4.

The modeling of two different separation processes in comparison with heat engine operating between highest temperature limits is presented in Fig. 5. In case of a thermally driven MED cycle, it can be represented by a

\begin{tabular}{|lccc|}
\hline Table 3. & State points of CCGT + Desalination cycle under analysis \\
\hline State & $\mathrm{m}(\mathrm{kg} / \mathrm{s})$ & $T(\mathrm{~K})$ & $P$ (bar) \\
\hline 1 & 768.71 & 305 & 1 \\
2 & 768.71 & 592 & 8 \\
3 & 1025.0 & 1470 & 8 \\
4 & 1025.0 & 911 & 1.2 \\
4 & 1025.0 & 370 & 1.2 \\
5 & 224.4 & 833 & 113 \\
6 & 224.4 & 723 & 28 \\
7 & 224.4 & 833 & 28 \\
a & 4.17 & 673 & 17 \\
At bleed point (a) & 220.23 & 673 & 17 \\
8 & 220.23 & 583 & 10 \\
$\mathrm{~b}$ & 70.36 & 400 & 2.7 \\
At bleed point (b) & 149.87 & 400 & 2.7 \\
9 & 149.87 & 319 & 0.1 \\
\hline
\end{tabular}

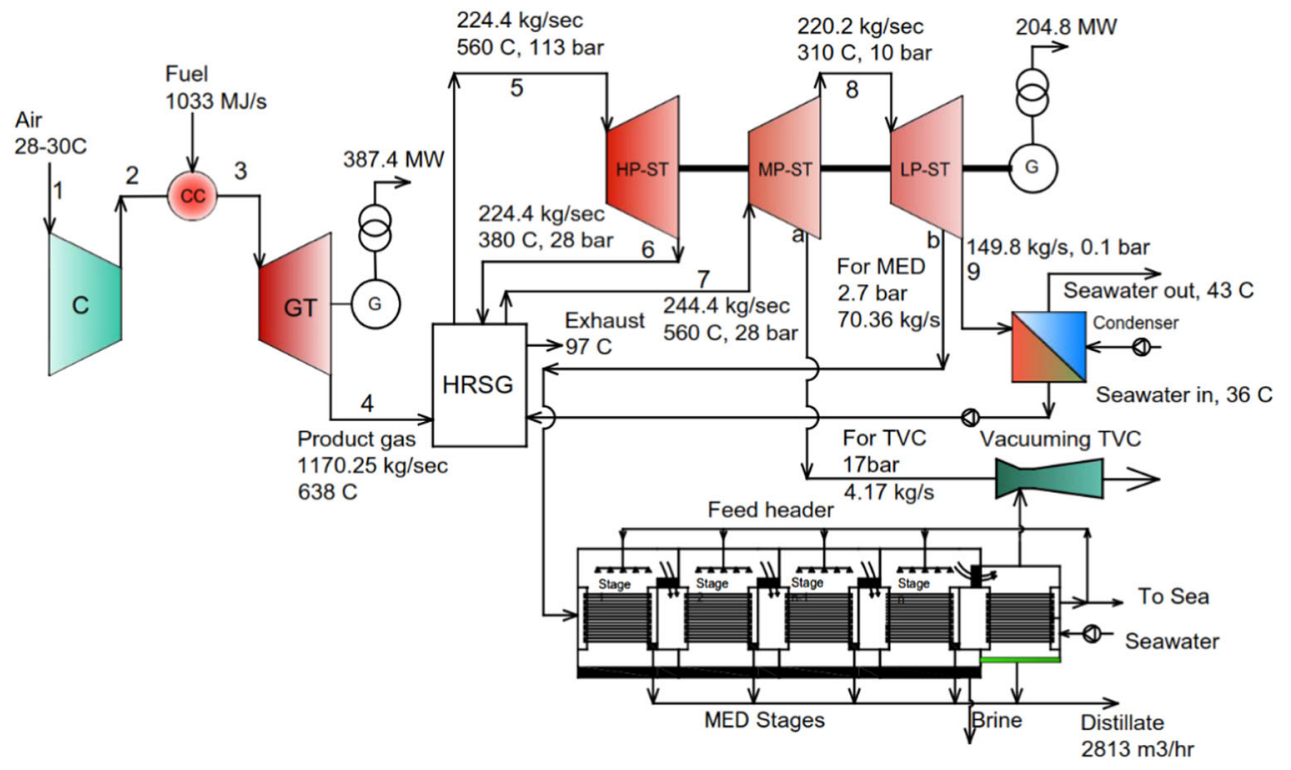

Fig. 4 Typical CCGT + desalination cycle configuration and operational parameters 
Table 4. Proposed methodology to calculate exergetic proportions of working steams

Gas turbine cycle

Carnot work

Second law efficiency

Exergy utilization factor for

GT cycle

Standard primary energy

conversion

$$
\begin{aligned}
& W_{\text {carnot }}^{G T}=\left(1-\frac{T_{o}}{T_{H}^{0}}\right) Q_{H}^{o} . \\
& \eta_{\Xi, G T}^{\pi}=\frac{\Xi_{a}}{\bar{\Xi}_{\text {rev }}} \approx \frac{W_{o}}{W_{\text {cov }}^{G T}} . \\
& \% \text { of Exergy utilization }=\frac{W_{\text {carnot }}^{G T}}{Q_{H}^{O}}+\% \text { of UL. } \\
& W_{\text {carnot }}^{G T}=\left(Q_{\mathrm{SPE}}^{\mathrm{GT}}\right)\left(1-\frac{T_{o}}{T_{\text {adia }}}\right) \eta_{\Xi, \mathrm{SPE}}^{\pi} .
\end{aligned}
$$

Steam turbine cycle

\section{Carnot work}

Second law efficiency

Exergy utilization factor for ST cycle

Standard primary energy conversion

$$
\begin{aligned}
& W_{\text {carnot }}^{S T}=\left(1-\frac{T_{o}}{T_{H}^{0}}\right)\left(Q_{H}^{o}-Q^{G T}\right) . \\
& \eta_{\Xi, S \mathrm{~T}}^{\underline{\pi}}=\frac{\Xi_{a}}{\bar{\Xi}_{\text {rev }}} \approx \frac{W_{a}^{H}}{W_{\text {rev }}^{\text {ST }}} . \\
& \% \text { of Exergy utilization }=\frac{W_{\text {camot }}^{\text {sT }}}{\left(Q_{H}^{\circ}-Q^{G T}\right)}+\% \text { of UL. } \\
& W_{\text {carnot }}^{\mathrm{ST}}=\left(Q_{\mathrm{SPE}}^{\mathrm{ST}}\right)\left(1-\frac{T_{o}}{T_{\text {ddia }}}\right) \eta_{\Xi, \mathrm{SPE}}^{\pi} .
\end{aligned}
$$

Separation/desalination cycle

Carnot work for separation

Second law efficiency of separation

For the same equivalent work, the standard primary energy is given by: $W_{\text {carnot }}^{\text {Sep }}=\left(Q_{\mathrm{SPE},}^{\text {sep }}\right)\left(1-\frac{T_{0}}{T_{\mathrm{adia}}}\right) \eta_{\Xi, \mathrm{SPE}}^{\pi}$.

$\eta_{\equiv, \text { sep }}^{\pi}=\frac{W_{\text {carnot }}^{\text {Sep }}}{\left(Q_{a,}^{\text {sep, } T_{\text {sep }}}\right)\left(1-\frac{T_{o}}{\text { Isep }_{\text {sep }}}\right)}$.

Actual separation work

$W_{\text {actual }}^{\text {Sep }}=\frac{W_{\text {carnot }}^{\text {Sep }}}{\eta_{\Xi \text { SPEE }}^{\pi}}$.

SPE proportions for separation processes $S P E_{M E D}=\frac{Q_{S P E}^{\text {sep, }}}{Q_{H}^{E}}+\%$ of UL

UL un-accounted losses that includes; (a) exhaust gas exergy leaving from HRSG at $97^{\circ} \mathrm{C}$, (b) losses in GT cycle, (c) losses in ST cycle and (d) steam exergy dumped in the condenser

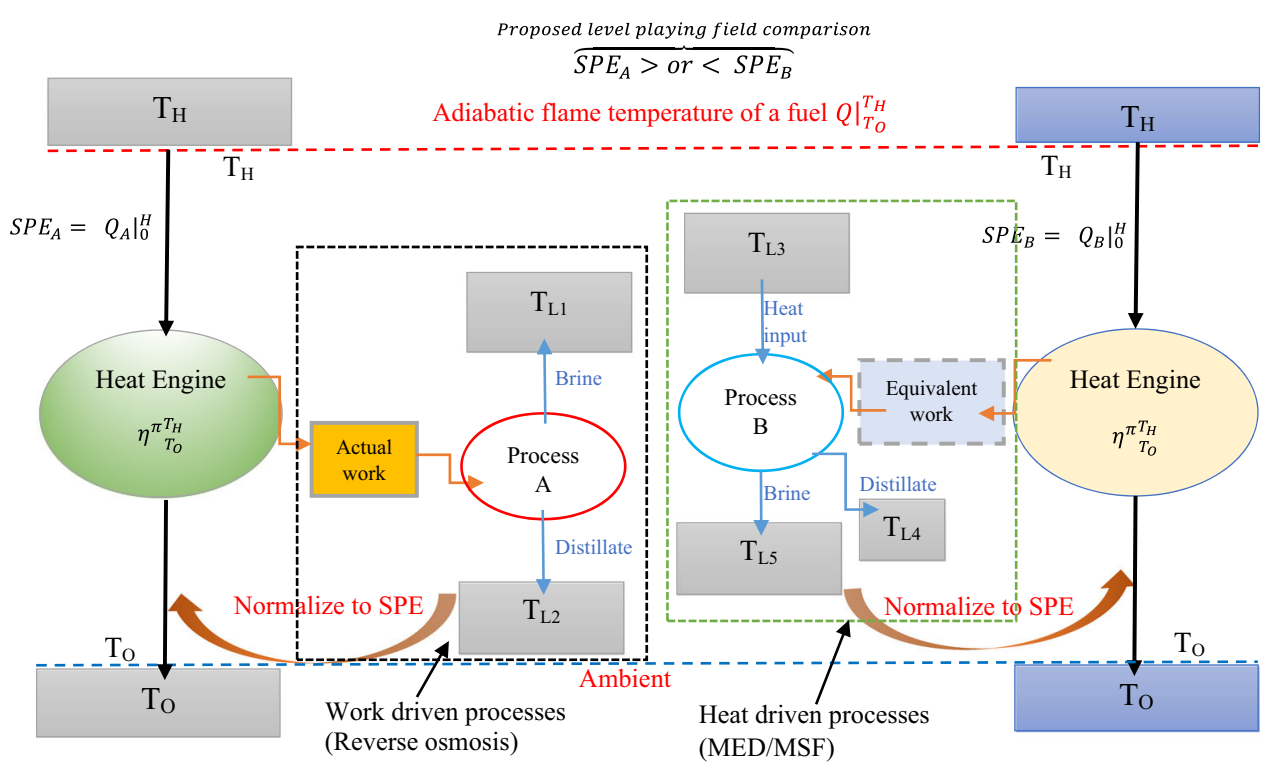

Fig. 5 The standard primary energy (SPE) consumption concept to emulate an actual desalination device using the equivalent work approach

heat engine that operates between the higher $\left(T_{\mathrm{L} 1}\right)$ and lower $\left(T_{\mathrm{L} 2}\right)$ temperature reservoirs. The heat engine extract a similar amount of derived energy $\left.Q\right|_{T_{12}} ^{T_{12}}$ as the MED as well as producing an arbitrary work $\left(W_{a}\right)$. As the derived energy for a thermally driven desalination process differs in energy grade as compared to the electricity, the same arbitrary work could be simulated by a heat engine that straddled between the temperature reservoirs of the SPE. This is performed by invoking the $2^{\text {nd }}$ Law efficiency where the primary energy $\left(\left.Q_{\mathrm{SPE}}\right|_{T_{0}} ^{T_{H}}\right)$ for the same work output can now be determined at the common platform conditions. Hence, by transforming thermodynamically all forms of derived energy supplied to the desalination processes, such as the work-driven or the heat-driven separation methods into the SPE, a common platform for efficacy comparison is established. The proposed common platform will serve to evaluate all kind of desalination processes at fair basis irrespective of process of separation. In closing, the short coming of quantifying the derived energy alone has been clarified. A thermodynamically rigorous method, namely the translation from the derived or secondary energy to a common platform of standard primary energy (SPE) consumption, is absolutely necessary in providing a just efficacy comparison of all desalination processes. 


\section{DATA AVAILABILITY}

The data that support the analysis and findings of this study are available from the corresponding author upon request.

\section{ACKNOWLEDGEMENTS}

The authors would like acknowledge KAUST for hybrid MEDAD cycle experiment pilot grants.

\section{AUTHOR CONTRIBUTIONS}

K.C.N. and M.W.S. proposed the idea of this work. M.W.S. developed detailed methodology with K.C.N.. M.B. helped in data collection and M.W.S. analyzed the data and drafted manuscript. K.C.N. have done the critical revision of the article and M.W.S. has done the final correction of the manuscript and approved the version to be published.

\section{ADDITIONAL INFORMATION}

Competing interests: The authors declare no competing interests.

Publisher's note: Springer Nature remains neutral with regard to jurisdictional claims in published maps and institutional affiliations.

\section{REFERENCES}

1. Trieb, F., Muller-Steinhagen, H. \& Müller-Steinhagen, H. Concentrating solar power for seawater desalination in the Middle East and North Africa. Desalination 220, 165-183 (2008).

2. Miller, S., Shemer, H. \& Semiat, R. Energy and environmental issues in desalination. Desalination 366, 2-8 (2015).

3. Sanz, M. A. (IDA President), Trends in desalination \& water reuse, Singapore International Water Week, 2018. https://www.siww.com.sg/docs/default-source/ default-document-library/mr-miguel-sanz.pdf?sfvrsn $=2$.

4. Shahzad, M. W., Burhan, M., Ang, L. \& Ng, K. C. Energy-water-environment nexus underpinning future desalination sustainability. Desalination 413, 52-64 (2017).

5. Ghaffour, N., Missimer, T. M. \& Amy, G. Technical review and evaluation of the economics of water desalination: current and future challenges for better water supply sustainability. Desalination 309, 197-207 (2013).

6. Elimelech, M. \& Phillip, W. A. The future of seawater desalination: energy, technology, and the environment. Science 333, 712-717 (2011).

7. Darwisha, M. A., Abdulrahim, H. K., Hassan, A. S. \& Sharif, A. O. Retrofitting the combined-cycle producingelectric power and desalted seawater to include district cooling in GCC. Desalin. Water Treat. 57, 1-4 (2015).

8. Buggea, J., Kjæra, S. \& Blumb, R. High-efficiency coal-fired power plants development. Energy 31, 1437-1445 (2006).

9. Fu, C., Anantharaman, R., Jordal, K. \& Gundersen, T. Thermal efficiency of coalfired power plants: from theoretical to practical assessments. Energy Convers. Manag. 105, 530-544 (2015).

10. Power Generation from Coal Measuring and Reporting Efficiency Performance and $\mathrm{CO}_{2}$ Emissions, The International Energy Agency (IEA) Report, Paris, (2010).

11. $\mathrm{CO}_{2}$ emissions from fuel combustion, The International Energy Agency (IEA) Report, Paris, (2017).

12. Hammond, G. P., Howard, H. R. \& Jones, C. I. The energy and environmental implications of UK more electric transition pathways: a whole systems perspective. Energy Policy 52, 103-116 (2013).

13. Hammond, G. P. \& O'Grady, Á. The implications of upstream emissions from the power sector. Energy 167-1, 9-19 (2014).

14. D. L. Chase. Combined-Cycle Development Evolution andFuture, GE Power Systems, GER-4206, (10/00). (GE Power Systems Schenectady, NY, 2000).

15. Almutairi, A., Pilidis, P. \& Al-Mutawa, N. Energetic and exergetic analysis of combined cycle power plant: part-1 operation and performance. Energies 8 , 14118-14135 (2015).

16. Breaking the power plant efficiency record, 9HA.01/.02 Gas Turbine, GE Power, March-2018.

17. Almutairi, A., Pilidis, P., Al-Mutawa, N. \& Al-Weshahi, M. Energetic and exergetic analysis of cogeneration power combined cycle and ME-TVC-MED water desalination plant: Part-1 operation and performance. Appl. Therm. Eng. 103, 77-91 (2016).

18. Hamed, O. A. Thermoeconomic analysis of combined power cycle integrated with MSF/SWRO desalination plant. Desalin. Water Treat. 57, 26552-26561 (2016).

19. Burley, M. J. Analytical comparison of the multi-stage flash and long-tube vertical distillation processes. Desalination 2-1, 81-88 (1967).
20. Al-Sofi, M. A. K. \& Srouji, M. M. Fuel allocation in dual-purpose plants. Desalination 100, 65-70 (1995).

21. Wang, Y. \& Lior, N. Fuel allocation in a combined steam-injected gas turbine and thermal seawater desalination system. Desalination 214, 306-326 (2007).

22. Hamed, O. A., Al-Washmi, H. A. \& Al-Otaibi, H. A. Thermo economic analysis of a power/water cogeneration plant. Energy 31, 2699-2709 (2006).

23. Helal, A. M. Hybridization-a new trend in desalination. Desalin. Water Treat. 3(1-3), 129-135 (2009).

24. Lozano, M. A., Carvalho, M. \& Serra, L. M. Allocation of economic costs in trigeneration systems at variable load conditions. Energy Build. 43, 2869-2881 (2011).

25. Spiegler, K. S. \& El-Sayed, Y. M. The energetics of desalination processes. Desalination 134, 109-128 (2001).

26. Mistry, K. H., Lienhard V, J. H. \& Zubair, S. M. Effect of entropy generation on the performance of humidification-dehumidification desalination cycles. Int. J. Therm. Sci. 49, 1837-1847 (2010).

27. Alasfour, F., Darwish, M. \& Amer, A. B. Thermal analysis of ME-TVC+MEE desalination systems. Desalination 174, 39-61 (2005).

28. Kahraman, N. \& Cengel, Y. A. Exergy analysis of a MSF distillation plant. Energy Convers. Manag. 46, 2625-2636 (2005).

29. Veza, J. M. Mechanical vapour compression desalination plants-a case study. Desalination 101, 1-10 (1995).

30. Cerci, Y. Exergy analysis of a reverse osmosis desalination plant in California. Desalination 142, 257-266 (2002).

31. Sharqawy, M. H., Zubair, S. M. \& Lienhard V, J. H. Second Law analysis of reverse osmosis desalination plants: an alternative design using pressure retarded osmosis. Energy 36-11, 6617-6626 (2011).

32. Lienhard, J. H., Mistry, K. H., Sharqawy, M. H. \& Thiel, G. P. Thermodynamics, exergy, and energy efficiency in desalination systems, DesalinationSustainability: A Technical, Socioeconomic, and Environmental Approach, (Elsevier Publishing Co., India, 2017), pp. 1-85 Ch 4, ISBN: 978-0-12-809791-5.

33. Mistry, K. H. et al. Entropy generation analysis of desalination technologies. Entropy 13-10, 1829-1864 (2011).

34. Mistry, K. \& Lienhard V, J. H. Generalized least energy of separation for desalination and other chemical separation processes. Entropy 15-6, 2046-2080 (2013).

35. Mistry, K., Antar, M. A. \& Lienhard V, J. H. An improved model for multiple effect distillation. Desalin. Water Treat. 51, 807-882 (2013).

36. Fitzsimons, L., Corcoran, B., Young, P. \& Foley, G. Exergy analysis of water purification and desalination: A study of exergy model approaches. Desalination 359, 212-224 (2015).

37. Shahzad, M. W., Burhan, M., Son, H. S., Oh, S. J. \& Ng, K. C. Desalination processes evaluation at common platform: a universal performance ratio (UPR) method. Appl. Therm. Eng. 134, 62-67 (2018).

38. Ng, K. C., Shahzad, M. W., Son, H. S. \& Hamed, O. A. An exergy approach to efficiency evaluation of desalination. Appl. Phys. Lett. 110, 184101-184105 (2017).

39. Semiat, R. Energy issues in desalination processes. Environ. Sci. Technol. 42-22, 8193-8201 (2008)

40. Stillwell, A. S. \& Webber, M. E. Predicting the specific energy consumption of reverse osmosis desalination. Water 8, 601-619 (2016).

41. Darwish, M. A. \& Alsairafi, A. Technical comparison between TVC/MEB and MSF. Desalination 170, 223-239 (2004).

42. Thu, K., Kim, Y.-D., Shahzad, M. W., Saththasivam, J. \& Ng, K. C. Performance investigation of an advanced multi-effect adsorption desalination (MEAD) cycle. Appl. Energy 159, 469-477 (2015).

43. Shahzad, M. W., Kyaw, T., Kim, Y.-d \& Ng, K. C. An experimental investigation on MEDAD hybrid desalination cycle. Appl. Energy 148, 273-281 (2015).

44. Ng, K. C. et al. Recent developments in thermally-driven seawater desalination: energy efficiency improvement by hybridization of the MED and AD cycles. Desalination 356, 255-270 (2015).

45. Shahzad, M. W., Ng, K. C., Kyaw, T., Saha, B. B. \& Chun, W. G. Multi Effect Desalination and Adsorption Desalination (MEDAD): a hybrid desalination method. Appl. Therm. Eng. 72, 289-297 (2014).

46. Shahzad, M. W. The hybrid multi-effect desalination (MED) and the adsorption (AD) cycle for desalination, Doctoral Thesis, National University of Singapore, Singapore (2013).

47. Mabrouk, A. N. \& Fath, H. E. S. Technoeconomic study of a novel integrated thermal MSF-MED desalination technology. Desalination 371, 115-125 (2015).

48. Leon Awerbuch and Corrado Sommariva, MSF distillate driven desalination process and apparatus, Patent No. PCT/GB2005/003329.

49. Nafeya, A. S., Fathb, H. E. S. \& Mabrouk, A. A. Thermoeconomic investigation of multi effect evaporation (MEE) and hybrid multi effect evaporation-multi stage flash (MEEMSF) systems. Desalination 201, 241-254 (2006).

50. Helal, A. M., El-Nashar, A. M., Al-Katheeri, E. \& Al-Malek, S. Optimal design of hybrid RO/MSF desalination plants Part I: modeling and algorithms. Desalination 154, 43-66 (2003). 
51. Hamed, O. A., Hassan, A. M., Al-Shail, K. \& Farooque, M. A. Performance analysis of a trihybrid NF/RO/MSF desalination plant. Desalin. Water Treat. 1, 215-222 (2009).

52. Hamed, O. A. Overview of hybrid desalintion systems-current status and future prospects. Desalination 186, 207-214 (2005).

53. Helal, A. M., E-Nashar, A. M., A-Katheeri, E. S. \& A-Malek, S. A. Optimal design of hybrid RO/MSF desalination plants Part III: sensitivity analysis. Desalination 169, 43-60 (2004).

54. Al-Mutaz, I. S. Hybrid RO MSF: a practical option for nuclear desalination. International. J. Nucl. Desalin. 1, 47-57 (2003).

55. Calì, G., Fois, E., Lallai, A. \& Mura, G. Optimal design of a hybrid RO/MSF desalination system in a non-OPEC country. Desalination 228, 114-127 (2008).

56. Cardona, E., Culotta, S. \& Piacentino, A. Energy saving with MSF-RO series desalination plants. Desalination 153, 167-171 (2002)

57. Hummer, G., Rasaiah, J. C. \& Noworyta, J. P. Water conduction through the hydrophobic channel of a carbon nanotube. Nature 414, 188-190 (2001)

58. Holt, J. K. et al. Fast mass transport through sub-2-nanometer carbon nanotubes. Science 312, 1034-1037 (2006).

59. Pendergast, MaryTheresa M. \& Hoek, E. M. V. A review of water treatment membrane nanotechnologies. Energy Environ. Sci. 4, 1946-1971 (2011).

60. Agre, P., Sasaki, S. \& Chrispeels, M. J. Aquaporins: a family of water channel proteins. Am. J. Physiol. Ren. Physiol. 265, 265-270 (1993).
61. Kaufman, Y., Berman, A. \& Freger, V. Supported lipid bilayer membranes for water purification by reverse osmosis. Langmuir 26, 7388-7395 (2010).

62. Fane, T. Overview and roadmap for membrane process development in desalination. DesalTech 2015, San Diego, USA Aug 28-29 (2015).

Open Access This article is licensed under a Creative Commons Attribution 4.0 International License, which permits use, sharing, adaptation, distribution and reproduction in any medium or format, as long as you give appropriate credit to the original author(s) and the source, provide a link to the Creative Commons license, and indicate if changes were made. The images or other third party material in this article are included in the article's Creative Commons license, unless indicated otherwise in a credit line to the material. If material is not included in the article's Creative Commons license and your intended use is not permitted by statutory regulation or exceeds the permitted use, you will need to obtain permission directly from the copyright holder. To view a copy of this license, visit http://creativecommons. org/licenses/by/4.0/.

(c) The Author(s) 2019 